\title{
A Muffler with Adaptive Acoustic Properties
}

\author{
Peter Šteblaj* - Mirko Čudina - Primož Lipar - Jurij Prezelj \\ University of Ljubljana, Faculty of Mechanical Engineering, Slovenia
}

An adaptive muffler upgrades the conventional muffler with a variable geometry to extend its working range. Adaptive muffler systems, described in the available literature, operate on the principle of controlling only a single property of the muffler to tune its working range. During the adaptation process of these systems, the basic principle of operation is not changed. Based on the literature review, the question arises of whether it would be possible to control the principle of operation. At one instant it would work as a Helmholtz resonator, in the other as an expansion chamber or side branch resonator. Analytical calculations provided a positive answer, and a muffler with four active valves was designed and constructed to confirm the theoretical expectations. The properties of proposed muffler were simulated with the Finite Element Method, and the results of simulations were validated with measurements. Finally, simulations of the proposed muffler were performed, working at different operating condition. Simulations have shown that the proposed system allows the tuning of the muffler to a wide working frequency range. Such an approach to muffler design eliminates the need for additional mufflers in IC exhaust systems. Therefore, a smaller volume of the proposed muffler enables the same effect as multiple non-adaptive conventional mufflers.

Keywords: adaptive muffler, hybrid muffler, noise control, exhaust system

Highlights

- The proposed adaptive muffler can be adjusted to specific noise by changing its operating principle, instead of only changing one of its properties.

- The active algorithm sets discrete values of valves instead of generating a signal for the actuator.

- The adaptation speed of the algorithm is very fast.

- The adaptive muffler can be smaller in comparison to conventional mufflers.

\section{O INTRODUCTION}

Engine exhaust is one of the dominant noise sources of vehicles. Different exhaust systems with mufflers are being developed to reduce this noise, in order to meet the required noise levels and sound quality. Their design is simultaneously optimized to minimize the pressure drop in the exhaust system. Muffler design is usually based on the theory of four reactive resonators; the Helmholtz resonator, the expansion chamber, the side branch resonator, and the Herschel-Quincke tube [1] and [2].

The optimization of the conventional reactive muffler with a fixed geometry for acoustic performance and low production costs is a complex task, [3] and [4], the result of which is usually a complicated internal geometrical structure, which increases backpressure. A muffler in the exhaust system of an internal combustion (IC) engine reduces its power and increases fuel consumption [1] and [5]. The engine power loss due to such a conventional passive exhaust muffler system is known to be at least $10 \%$ [1] and [6]. Dual mode mufflers [7] and reactive mufflers with various internal configurations [5] have been proposed to reduce the problems caused by the high backpressure of conventional mufflers, but with only limited success. To overcome this problem, active noise control (ANC) systems were developed. They are an up-to-date alternative for classical reactive resonators. ANC is a method for reducing unwanted noise with its "antinoise", which is specifically calculated and generated to be a copy of unwanted noise with a reversed phase. ANC can be applied in various situations for suppressing unwanted noise [8], and is widely used in cabins [9] and [10], in ducts [11] and [12] and also in engine exhaust systems [13] and [14]. The ANC method applied to vehicle exhaust noise reduction has some advantages, such as no increase in the exhaust backpressure, improving the performance of the engine, and reducing fuel consumption. Furthermore, it may make the structure of the active muffler compact and facilitate its installation [13]. Such mufflers have been continually improved in recent years. Mufflers with ANC use specially designed loudspeakers to generate "antinoise" to cancel the exhaust noise. Such loudspeakers have to reproduce noise and withstand high temperatures and pressure pulsations. Despite positive results in the laboratory and in actual carinstallation, this method has thus far failed to be widely commercialized for applications in exhaust systems.

In recent years, a great deal of effort has been put into the research of adaptive reactive mufflers [6], [11], [15] and [16]. Instead of loudspeakers, adaptive mufflers use non-acoustic actuators to eliminate the 
problems of acoustic feedback, which is one of the prevailing problems in the practical usage of ANC. The main advantage of the adaptive muffler is its ability to control its effects in real time and consequently achieve higher noise reduction for different input noises. Its efficiency in noise reduction can be tuned to desired levels and/or to the welfare of the users' subjective expectations. Different algorithms for adaptive tuning of mufflers by controlling different physical properties are constantly being developed.

In previous literature, Bartlett and Whalley [17] developed the mathematical background for the variable geometry of exhaust systems. Chiu and Chang [4] proposed shape optimization of the muffler within limited space using a simulated annealing (SA) method. Chiu [3] also used the SA method to optimize broadband noise with multiple tones. Hwang et al. [6] proposed a method using actively controlled U-shape bypass pipes. Cherrier et al. [18] created perforated panel resonators with an active control of their openings (so-called necks). Chen and Too [11] combined the principle of the reactive muffler with an actively controlled loudspeaker. Kostek and Franchek [19] proposed a hybrid resonator with an actively controlled cavity of the Helmholtz resonator. Howard and Craig [15] and [20] presented an adaptive quarterwave resonator to attenuate the exhaust noise of a V6 petrol engine, adapting to changes in engine operating conditions (revolutions per minute (RPM) and load), and exhaust gas temperature.

In the available literature on adaptive mufflers, the main acoustic path is always manipulated in order to increase transmission loss (TL) at different operating conditions. Such systems are able to adapt to the current operating condition and their noise attenuation is increased in the overall frequency range.

In this article, a new idea of adapting the mufflers' acoustic properties is presented. Adaptation is achieved with the redirection of the stream flow by using the actively controlled valves. The idea is to use the valves to change the principle of the noise attenuation mechanism in real time. The system attenuates the sound propagation by using the Helmholtz resonator at one moment; at the next moment, the system can switch to work as an expansion chamber or quarter wavelength resonator. With such an approach, noise reduction can be tuned to various operating conditions without an increase of backpressure or reduction in engine performance. The proposed adaptive muffler with active flow valves (V1-4) is presented in Fig. 1. The configuration in Fig. 1 was used to include four basic theoretical principles of reactive mufflers: Helmholtz resonator, expansion chamber, side-branch resonator $(\lambda / 4)$, and HerschelQuincke tube. Geometry, positions and the number of valves can be optimized according to the demands of the working environment. Control of the reactive noise attenuation principle within one dynamic system is an optimization problem similar to the current approach [3] and [4].

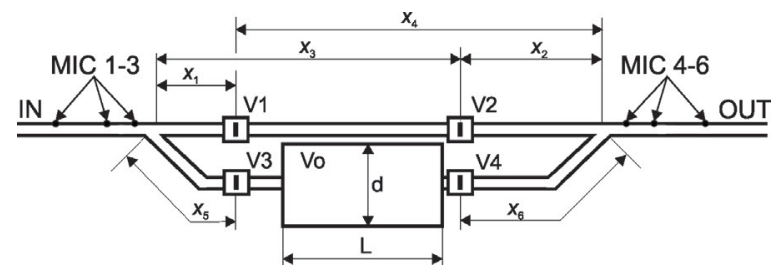

Fig. 1. Proposed adaptive muffler with active flow valves

The confirmation of the hypothesis presented in this paper was confirmed with four individual approaches: 1) analytical calculation, 2) experiment, 3) numerical simulations of steady state operation using the finite element method (FEM), and 4) numerical simulation of transient effects. All four individual approaches provide encouraging results for the implementation of the proposed system into production.

\section{ANALYTICAL CALCULATION}

Reactive mufflers are designed to reduce plane sound wave propagation. Their design is based either on the principle of the Helmholtz resonator, the expansion chamber, the quarter wavelength resonator or, in special cases, the Herschel-Quincke tube. In general, the Helmholtz resonator (HR) is suitable for attenuating the lowest discrete frequencies with high amplitudes [21]. Some designs of HR are composed of several resonators of different sizes to target a broader range of frequencies. Expansion chamber mufflers have an effect in broadband frequency range and have no effect when the product of $k L$ is equal $\pi, 2 \pi, 3 \pi$, etc. Davis et al. [22] reported that their performance can deteriorate at higher frequencies when the crosssection dimension of the muffler reaches $82 \%$ of the acoustic wavelength.

Quarter wavelength resonators are effective in attenuating a discrete noise and its higher oddharmonics. Herschel-Quincke tubes are also suitable for discrete noise and its higher harmonics [16]. However, these types of non-adaptive resonators have limited application for noise sources with variable discrete frequencies. 
The proposed system (Fig. 1) consists of an inlet pipe, three microphones (MIC 1 to 3) for measuring the incident and reflected sound wave propagation at the input, four valves (V1 to V4) for redirecting the main stream flow, an expansion chamber with interconnecting pipes, an outlet pipe, and three microphones (MIC 4 to 6 ) for measuring the transmitted sound waves at the output.

Sound propagates downstream to the first Y-junction, where it splits into two separate ways. One way is directly downstream, and the other is through the expansion chamber. $x_{1}, \ldots, x_{6}$ are the dimensions of individual reactive elements. The dimensionless ratios $x_{1} / x_{5}, x_{1} / x_{2}, x_{2} / x_{5}$, etc. are extremely important. They determine the attenuation of discreet frequencies. The optimization of this ratio depends on noise sources.

To predict the performance of a muffler, the transfer matrix method was used [23]. This method is recommended by various authors [2] to [4], [21], [24] and [25]. The sound pressure and the normal particle velocities upstream and downstream of the muffler can be expressed as a transfer matrix with Eq. (1):

$$
\left[\begin{array}{c}
P_{\mathrm{u}} \\
U_{\mathrm{u}}
\end{array}\right]=\left[\begin{array}{ll}
T_{11} & T_{12} \\
T_{21} & T_{22}
\end{array}\right]\left[\begin{array}{c}
P_{\mathrm{d}} \\
U_{\mathrm{d}}
\end{array}\right]
$$

where $P_{\mathrm{u}}$ and $U_{\mathrm{u}}$ represent the sound pressure and particle velocity in the upstream direction, and $P_{\mathrm{d}}$ and $U_{\mathrm{d}}$ represents the sound pressure and velocity in the downstream direction. Matrix $\mathbf{T}$ is a transfer matrix that is defined by the geometry and dimensions of the muffler. $T L$ is defined as the difference between the incident power on the muffler and the transmitted power into the downstream direction of the anechoic termination. The $T L$ of the expansion chamber can be expressed with Eq. (2)

$$
T L=10 \times \log \left(1+\frac{1}{4}\left(\frac{S_{1}}{S_{2}}-\frac{S_{2}}{S_{1}}\right)^{2} \sin ^{2} k L\right),
$$

where $S_{1}$ and $S_{2}$ are the cross-section of the duct before the expansion and cross-section after the expansion, respectively, $L$ is the length of the expansion chamber and $k$ is the wave number. $T L$ for the Helmholtz resonator can be written as:

$$
T L=10 \times \log \left(1+\frac{c^{2}}{4 S^{2}\left(\frac{\omega L^{\prime}}{S}-\frac{c^{2}}{\omega V}\right)}\right),
$$

where $\omega, c, V, S, L$ ' are the resonance frequency, the speed of sound, the volume of the cavity, the cross section of the neck, and the effective length of the resonator, respectively. The $T L$ of a quarter-wave resonator is:

$$
T L=10 \times \log \left(\frac{\left(\frac{R_{s}}{\rho_{0} c}+\frac{\pi a^{2}}{2 S}\right)^{2} \tan ^{2}\left(k L^{\prime}\right)+1}{\left(\frac{R_{\mathrm{s}}}{\rho_{0} c}\right)^{2} \tan ^{2}\left(k L^{\prime}\right)+1}\right),
$$

where $R_{\mathrm{s}}, S, L, a, \rho_{0} c_{0}$ are the specific acoustic resistance, the cross section of the main duct, the effective length and radius of the resonator and the specific acoustic impedance, respectively.

The analytical results of $T L$, as a function of frequency, are presented in Fig. 2 for four different reactive mufflers (Expansion chamber - solid line, Helmholtz resonator - dotted line, $\lambda_{1} / 4$ resonator dashed line, and $\lambda_{2} / 4$ - dash dotted line).

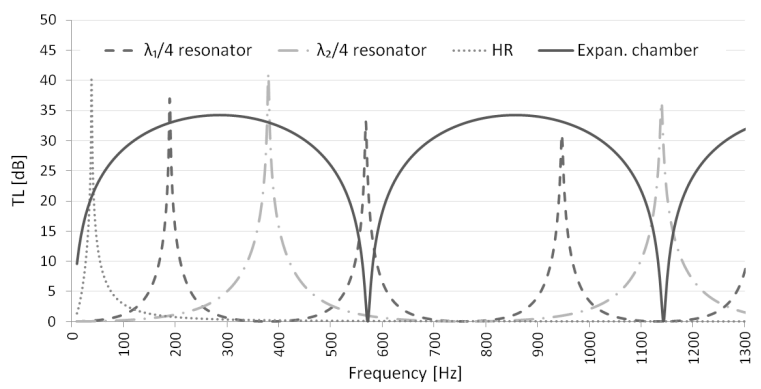

Fig. 2. Results of analytical calculations

The Helmholtz resonator is tuned to a selected frequency at which the system oscillates. More $\lambda / 4$ resonators are tuned to back up the performance of the expansion chamber at its $T L$ minima.

\section{EXPERIMENTAL SET-UP}

The modular construction of the experimental setup is presented in Fig. 3. It enables easy changing of the experimental configuration and measurements of different acoustical characteristics.

The dimensions of the muffler system are selected according to the demands of a typical IC exhaust system. The experimental setup was built from stainless steel pipes with a diameter of $\phi 48 \mathrm{~mm}$. Its total length was $3400 \mathrm{~mm}$, simulating an average vehicle exhaust system. For input noise simulation, a loudspeaker with a diameter of $\phi 120 \mathrm{~mm}$ was used. It was mounted in a 20 litre box. Pink noise was used as a test signal to excite the system and to measure $T L$, 
which was done in a frequency range from $10 \mathrm{~Hz}$ to $1200 \mathrm{~Hz}$.

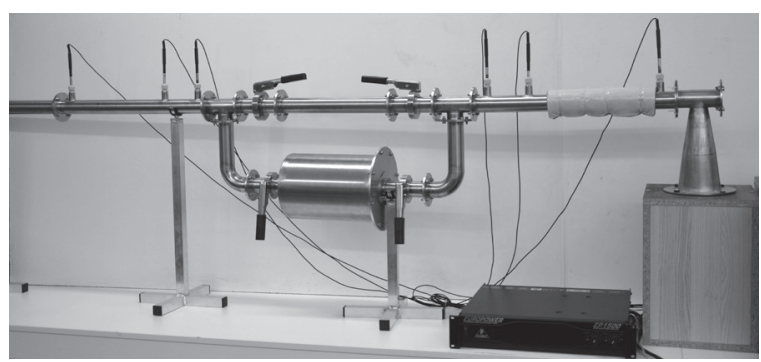

Fig. 3. Experimental set-up

Six microphones were used to measure the sound pressure field; three in the downstream direction and three upstream. Three microphones were used on each side of the muffler to overcome the inherent problems of measurements in the standing wave sound field.

\section{SIMULATIONS WITH FEM}

The boundary element method (BEM) and FEM are usually used to predict the performance of mufflers in frequency and in time domain analysis [26] and [27]. FEM analysis is better suited for our applications. It enables the evaluation of the validity of the results in the upper frequency range. It also enables the observation of the sound pressure standing waves, which are formed in duct systems.

When simulating a complex system, such as the one presented, there are many other influences on acoustic attenuation, such as the impedance of the wall, termination of the pipe, etc. Therefore, a validation of the FEM simulation was performed. FEM simulations were validated for the measurement set-up presented in Fig. 3. Validated FEM analyses were used to perform the frequency domain analysis, to determine the overall $\mathrm{TL}$ of the system, and to determine the transient effects of changing the position of the valves. Additional analysis was made to determine the influence of the valve position on overall transmission. The results of validation are presented in Fig. 4 for five different options of valve openings.

During the validation process of FEM simulations, it was shown that the frequency response of the noise source has to be taken into consideration. Therefore, a frequency response of the loudspeaker was included in the FEM model to obtain agreement between the measured and simulated results.

The validation process of FEM simulations also showed that a nonreflecting boundary condition, which

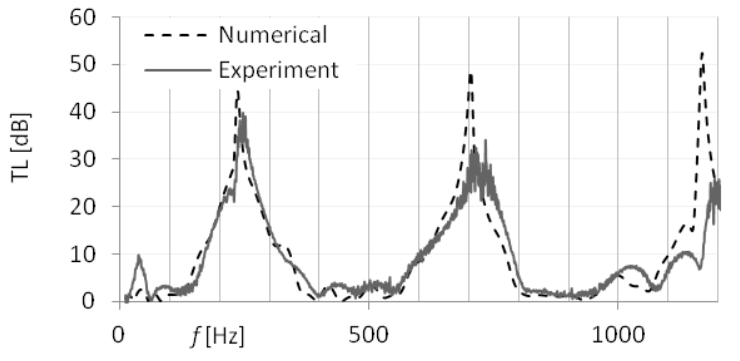

a)

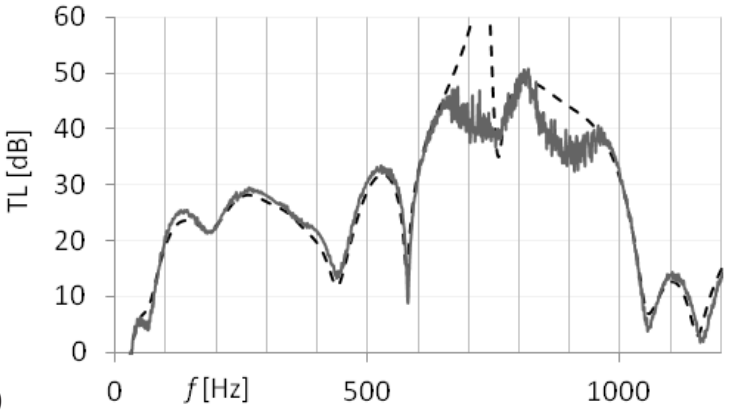

b)

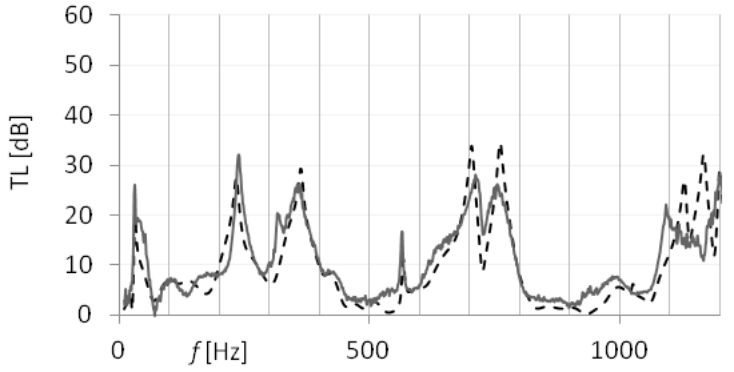

c)

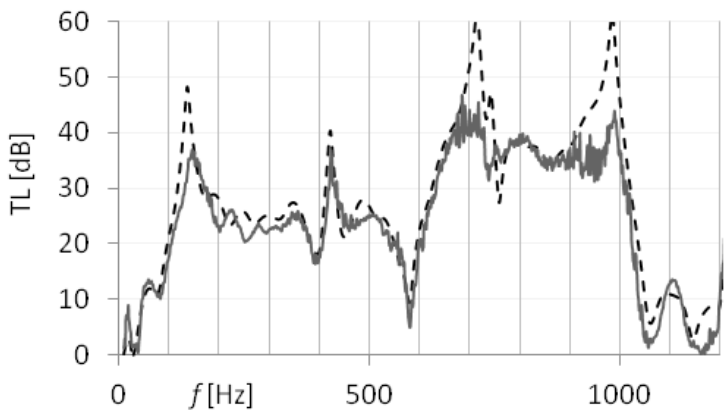

d)

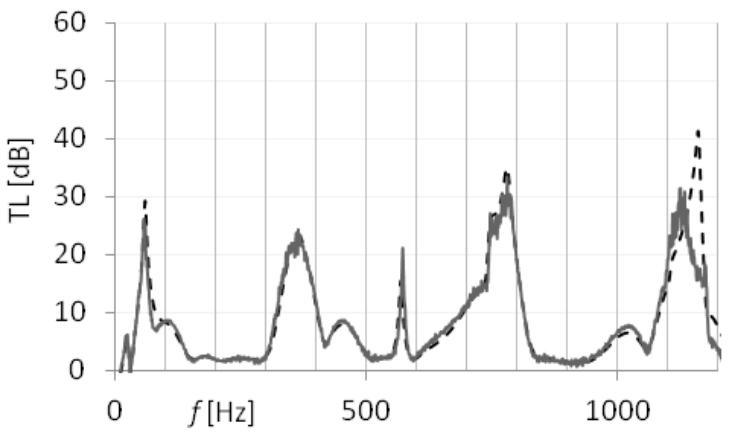

Fig. 4. Comparison between measured results and results of FEM analysis a) double $\lambda 1 / 4$ resonator, b) expansion chamber, c) Helmholtz resonator with $\lambda 1 / 4$ resonator, d) expansion chamber with $\lambda 2 / 4$ resonator, e) all open valves 
can be implemented as a perfectly matched layer [28], does not provide suitable results for the prediction of the internal acoustic field in the muffler. Therefore, in this study, anechoic termination was modeled using the sound absorption of porous material obtained with the Delany-Bazley model [29]. During the validation process of the FEM simulations, it was shown that the pipes used in the experimental set-up cannot be modeled with a rigid surface; therefore, an impedance boundary condition was used. The impedance of the pipes' surface was determined empirically. A very good agreement between results of the FEM analysis and measurement results on the experimental setup was thus achieved, as can be seen in Fig. 4.

The results of the analysis showed that opened valves have only a minor effect on the overall TL in the frequency range of interest. Their effect was neglected during the steady state calculations of the muffler TL.

Fig. 5 shows the maximum overall $T L$ of our system. With the presented configuration, up to $50 \mathrm{~dB}$ of TL was achieved in the frequency range observed.

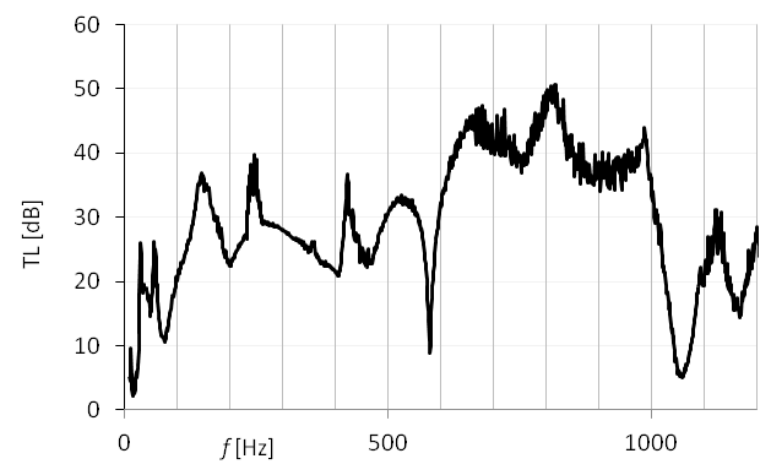

Fig. 5. Maximum overall expected TL based on measurement

\section{ADAPTIVE CONTROL OF MUFFLER}

For adaptive control of the valves, the active noise control approach (ANC) was used (Fig. 6a). A reference signal $x(t)$, which can be obtained from a reference microphone (MIC 1), is used to describe the input sound pressure.

$\mathrm{P}$ and $\mathrm{S}$ in Fig. 6a represent the transfer function of the primary path, which consists of the acoustic response from the measuring microphones to the error microphone. The primary acoustic path is composed of the fixed part $\mathrm{P}$ and variable part $\mathrm{S}$. $\mathrm{S}$ is the transfer function of the adaptive muffler. $\mathbf{S}$ ' is a matrix of estimated TL for each valve configuration. $\mathrm{C}$ is the controller for controlling the states of 4 valves. $e(t)$ is the error or the feedback of the effectiveness of TL detected by MIC 6. AA represents the adaptive algorithm which is used to track and adapt coefficients to current conditions. It is used in the case of the system property changes due to temperature difference, flow changes, or some other effects that influence the TL of the muffler.

The input signal $x(t)$ is obtained and processed on the secondary path. $\mathbf{K}$ represents the decision matrix in which the decision is made about which combination of valves is used (Fig. 6b). The spectrum is calculated from the input signal and compared to the known TL of each combination of valves. Utilizing the controller and its decision matrix, the system will choose which combination is the best to use. This decision matrix can be calculated using several decision criteria: the RMS of the spectrum, maximum sound pressure level, psychoacoustic criteria, or similar.

In this study, the muffler has five discrete options, depending on five combinations of the flow valves states. Its transmission losses are presented in Fig. 4.

a)
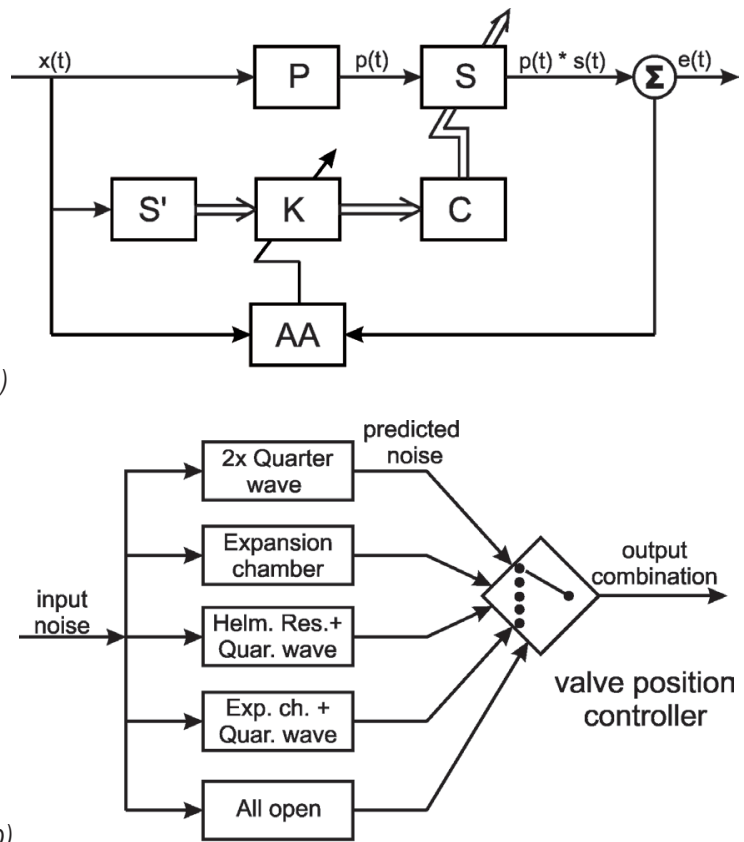

Fig. 6. Adaptive noise control principle: a) adaptive noise control algorithm, b) decision matrix

By adjusting four valves (V1 to V4) in the test setup, five different options of TL can be achieved (Fig. 1). The first option is for opened valves V1 and V3 and closed V2 and V4 (Fig. 4a). The second option is for closed valves V1 and V3 and for opened valves V2 and V4 (Fig. 4b). Stream propagation is altered through the expansion chamber, and results in the noise attenuation of the expansion chamber. An additional quarter-wave resonator can be used, whose length is determined by the position of $\mathrm{V} 1$ and V3. 
The third option is for closed valves V4 and for all the other valves opened (Fig. 4c). The expansion chamber acts as a cavity and the bent part of the pipe acts as a neck for the Helmholtz resonator. The bent part of the pipe acts as a single quarter wavelength resonator. This option is suitable for the lowest frequencies, such as for the tonal noise and its odd harmonics. The fourth option is for the closed valve V1 and for all the other valves opened (Fig 4d). This combination adds a quarter-wavelength resonator $(\lambda / 4)$ to the expansion chamber. The length of this quarter wavelength resonator can be altered by the positions of $\mathrm{V} 1$ and V3. The last, fifth, option is for all valves opened (Fig. 4e). In this case, the secondary path acts as a Herschel-Quincke tube with an additional expansion chamber in between.

\section{RESULTS OF TRANSIENT ANALYSIS}

Fig. 4 shows the TL of five different valve opening combinations. Valve combinations are selected using a decision matrix. The results of the decision matrix for the RMS of the spectrum are presented in Table 1. The RMS of each option is presented along with the decision matrix $\mathbf{K}$ selections. In this criterion, the RMS of the input noise spectrum was calculated and compared with the known TL for each option in the selected frequency range. Lower RMS means a smaller difference between the known TL and input spectrum, which are equal to greater overall noise attenuation (written in bold). For the test signal, six different input noises were used.

Table 1. Results of decision matrix for discrete input signals

\begin{tabular}{|c|c|c|c|c|c|c|c|}
\hline \multirow{2}{*}{$\begin{array}{l}\text { Freq } \\
{[\mathrm{Hz}]}\end{array}$} & \multirow{2}{*}{$\begin{array}{l}\text { Leq } \\
{[\mathrm{dB}]}\end{array}$} & \multicolumn{5}{|c|}{ Options } & \multirow{2}{*}{$\begin{array}{c}\mathrm{K} \\
\text { [opt.] }\end{array}$} \\
\hline & & 1 [dB] & $2[\mathrm{~dB}]$ & $3[\mathrm{~dB}]$ & $4[\mathrm{~dB}]$ & $5[\mathrm{~dB}]$ & \\
\hline 30 & 90 & 96.8 & 91.3 & 75.8 & 90.3 & 87.9 & 3 \\
\hline 50 & 90 & 93.4 & 84.2 & 83.4 & 77.4 & 73.6 & 5 \\
\hline 150 & 90 & 88.0 & 64.8 & 82.9 & 56.7 & 89.9 & 4 \\
\hline 250 & 90 & 57.4 & 63.6 & 68.5 & 71.1 & 89.8 & 1 \\
\hline 520 & 90 & 87.3 & 58.9 & 87.5 & 69.2 & 90.0 & 2 \\
\hline PN & 90 & 83.2 & 70.9 & 82.3 & 74.3 & 81.8 & 2 \\
\hline
\end{tabular}

Five of them were combined from pink noise with a pronounced discrete frequency tone. One signal contained only pink noise. All of the input noises had the same equivalent level of noise: $90 \mathrm{~dB}$. The results of the RMS of spectra are shown in Table 1 (columns 3 to 7 , options 1 to 5 ). The last column represents the outcome of the decision matrix selection. It is clear that the decision matrix result was always the lowest calculated RMS. For the final test signal, only pink noise was used and compared to the known TL.
To determine the optimal coefficients of the filter used for the specific frequency range, a band pass signal of pink noise with a bandwidth of $20 \mathrm{~Hz}$ and sound pressure level of $90 \mathrm{~dB}$ was swept through the frequency range of interest. The frequency range of interest was set from $10 \mathrm{~Hz}$ to $1200 \mathrm{~Hz}$. Fig. 7 represents the frequency response of the system on the input test signal; Line 1 is input test signal (horizontal line); Line 2 is output SPL (solid line); Line 3 is maximum TL (dash dot line). The output SPL is inversely proportional to maximum TL if the control system is tracking changes in real time. Vertical dashed lines represent the limits of individual option settings for specific frequency ranges. The optimal decisions for used algorithm are presented in Table 2. The performance of the system was tested with slow and fast changes of the input signal. During slow changes, the system had enough time to calculate optimal solutions. During fast changes, a time delay resulted in frequency shifts.

Table 2. Optimal $\mathrm{K}$ for specific frequency range

\begin{tabular}{cccc}
\hline$f_{\min }[\mathrm{Hz}]$ & $f_{\max }[\mathrm{Hz}]$ & $\Delta f[\mathrm{~Hz}]$ & $K_{\text {optimal }}$ \\
\hline 10 & 30 & 20 & 3 \\
\hline 30 & 60 & 30 & 5 \\
\hline 60 & 85 & 25 & 2 \\
\hline 85 & 190 & 105 & 4 \\
\hline 190 & 198 & 8 & 2 \\
\hline 198 & 250 & 52 & 1 \\
\hline 250 & 378 & 128 & 2 \\
\hline 378 & 450 & 72 & 4 \\
\hline 450 & 680 & 230 & 2 \\
\hline 680 & 685 & 5 & 4 \\
\hline 685 & 945 & 260 & 2 \\
\hline 945 & 1015 & 70 & 4 \\
\hline 1015 & 1045 & 30 & 2 \\
\hline 1045 & 1070 & 25 & 3 \\
\hline 1070 & 1150 & 80 & 5 \\
\hline 1150 & 1156 & 6 & 1 \\
\hline 1156 & 1190 & 34 & 3 \\
\hline 1190 & 1202 & 12 & 1 \\
\hline
\end{tabular}

Fast changes of the input signal were defined by the velocity of the frequency sweep. The velocity of slow changes was defined as $\mathrm{d} f / \mathrm{d} t=0 \mathrm{~Hz} / \mathrm{s}$. Fast changes were defined as $\mathrm{d} f / \mathrm{d} t=100 \mathrm{~Hz} / \mathrm{s}$ to 1000 $\mathrm{Hz} / \mathrm{s}$, which gives the system less time to calculate an optimal solution. The system response to fast changes is presented in Figs. 8 and 9. A system working under fast changes of input signals cannot follow the optimal working conditions fast enough. This can be seen as an increase of sound pressure level after each 
change of option. The time delay of control system reduces system performance. The velocity of changes in practical systems does not exceed $300 \mathrm{~Hz} / \mathrm{s}$. This gives our system enough time to adapt to changes in a real system.

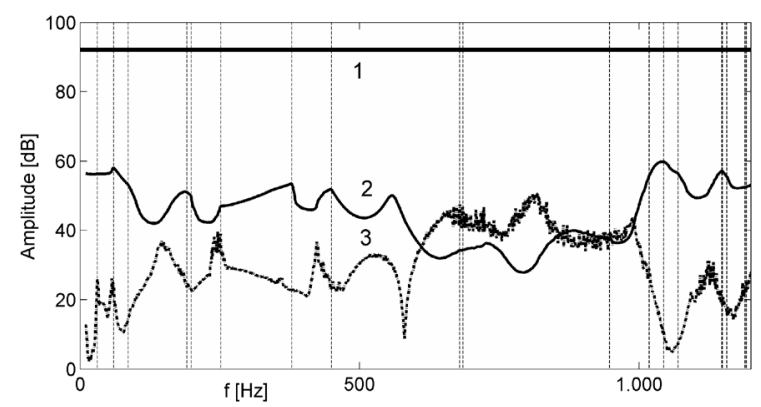

Fig. 7. Frequency response of proposed system on input signal

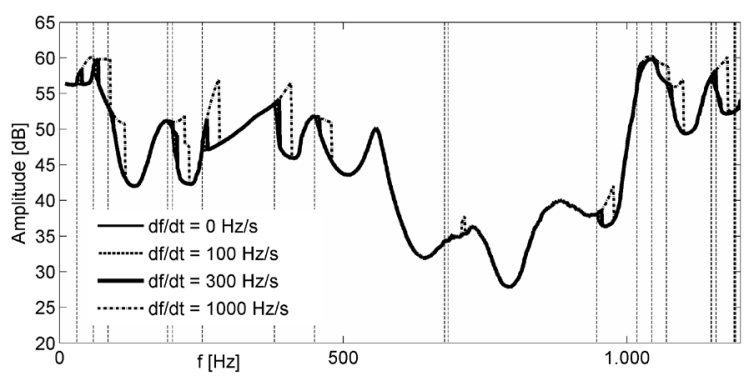

Fig. 8. Time delay of the control system is represented with frequency shift

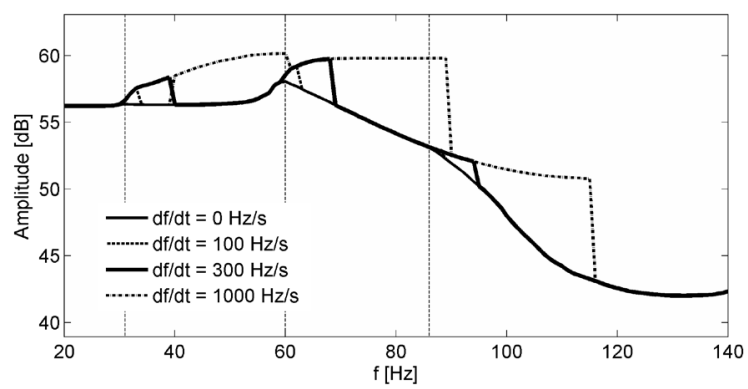

Fig. 9. Detailed time delay from Fig. 8 in frequency range $20 \mathrm{~Hz}$ to $140 \mathrm{~Hz}$ on performance delay of frequency shift

\section{CONCLUSIONS}

The idea presented in this article is to achieve an adaptive muffler system that is able to adapt to different operating conditions and noise perception. An adaptive muffler was designed to manipulate four different mechanisms of noise control. The dimensions of pipes, position and number of valves and their openings, and changes in the intersection of connecting elements can be optimized for the demands of noise control or for psychoacoustic criteria.
Combinations of multiple individual reactive mufflers can be used and controlled by a single actively controlled valve. The active noise control principle was implemented. The response of the proposed system was tested with different input signals. The performance of the system was also tested with slow and fast changes of the input signal to determine the overall stability. With the newly proposed approach, the multiple noise reduction principle can be used in one system. Therefore, a smaller volume of muffler enables the same effect as multiple non-adaptive reactive mufflers.

The principle of the actively controlled valve system can also be applied in the ducts of air conditioning systems or ventilation units where additional individual units are used for short periods of time or when operating conditions are changed.

\section{REFERENCES}

[1] Munjal, M. (1987). Acoustics of Ducts and Mufflers with Application to Exhaust and Ventilation System Design. John Wiley \& Sons, New York.

[2] Yasuda, T., Wu, C., Nakagawa, N., Nagamura, K. (2013). Studies on an automobile muffler with the acoustic characteristic of low-pass filter and Helmholtz resonator. Applied Acoustics, vol. 74, no. 1, p. 49-57, Dol:10.1016/j. apacoust. 2012.06.007.

[3] Chiu, M.C. (2013). Numerical assessment for a broadband and tuned noise using hybrid mufflers and a simulated annealing method. Journal of Sound and Vibration, vol. 332, no. 12, p. 2923-2940, DOI:10.1016/j.jsv.2012.12.039.

[4] Chiu, M.C., Chang, Y.C. (2008). Shape optimization of multichamber cross-flow mufflers by SA optimization. Journal of Sound and Vibration, vol. 312, no. 3, p. 526-550, DOl:10.1016/j.jsv.2007.11.003.

[5] Yu, X., Cheng, L. (2015). Duct noise attenuation using reactive silencer with various internal configurations. Journal of Sound and Vibration, vol. 335, p. 229-244, D0l:10.1016/j. jsv.2014.08.035.

[6] Hwang, Y., Lee, J., Min Kim, Seung-Jong (2003). New active muffler system utilizing destructive interference by difference of transmission paths. Journal of Sound and Vibration, vol. 262, no. 1, p. 175-186, Dol:10.1016/S0022460X(02)01378-0.

[7] Liu, B., Maeno, M., Hase, S., Wakamatsu, S. (2003). A study of a dual mode muffler. SAE Technical Paper, p. 1647, DOI:10.4271/2003-01-1647.

[8] Kuo, S.M., Morgan, D.R. (1996). Active Noise Control Systems Algorithms and DSP Implementations. John Wiley \& Sons, New York.

[9] Landaluze, J., Portilla, I., Pagalday, J.M., A. Martínez, A., Reyero, R. (2003). Application of active noise control to an elevator cabin. Control Engineering Practice, vol. 11, no. 12, p. 1423-1431, D0I:10.1016/S0967-0661(03)00077-7. 
[10] Tamamura, M., Shibata, E. (1996). Application of active noise control for engine related cabin noise. JSAE Review, vol. 17, no. 1, p. 37-43, D0l:10.1016/0389-4304(95)00047-X.

[11] Chen, S.R., Too, G.P.J. (2009). Simulations and experiments for hybrid noise control systems. Applied Acoustics, vol. 70, no. 2, p. 247-255, DOl:10.1016/j.apacoust.2008.04.005.

[12] Prezelj, J., Čudina, M. (2007). Dipole in orthogonal direction as a secondary source for active noise control in ducts. Acta Acustica united with Acustica, vol. 93, no. 1, p. 63-72.

[13] Li, K., Tanaka, T. (2001). Development of an adaptive control simulation system for vehicle exhaust noise reduction. JSAE Review, vol. 22, no. 2, p. 157-162, Dol:10.1016/S0389. 4304(00)00104-1.

[14] Cuesta, M., Cobo, P. (2001). Optimisation of an active control system to reduce the exhaust noise radiated by a small generator. Applied Acoustics, vol. 62, no. 5, p. 513-526, D0l:10.1016/S0003-682X(00)00060-8.

[15] Howard, C.Q., Craig, R.A. (2014). An adaptive quarter-wave tube that uses the sliding-Goertzel algorithm for estimation of phase. Applied Acoustics, vol. 78, p. 92-97, D0l:10.1016/j. apacoust.2013.12.002.

[16] Huang, L. (2009). Attenuation of low frequency duct noise by a flute-like silencer. Journal of Sound and Vibration, vol. 326, no. 1-2, p. 161-176, D0I:10.1016/j.jsv.2009.05.004.

[17] Bartlett, H., Whalley, R. (1998). Modelling and analysis of variable geometry exhaust gas systems. Applied Mathematical Modelling, vol. 22, no. 8, p. 545-567, Dol:10.1016/S0307904X(98)10056-2.

[18] Cherrier, O., Pommier-Budinger, V., Simon, F. (2012). Panel of resonators with variable resonance frequency for noise control. Applied Acoustics, vol. 73, no. 8, p. 781-790, D0l:10.1016/j.apacoust.2012.02.011.

[19] Kostek, T.M., Franchek, M.A. (2000). Hybrid noise control in ducts. Journal of Sound and Vibration, vol. 237, no. 1, p. 81100, D0l:10.1006/jsvi.2000.3056.

[20] Howard, C.Q., Craig, R.A. (2014). Noise reduction using a quarter wave tube with different orifice geometries.
Applied Acoustics, vol. 76, p. 180-186, D0l:10.1016/j. apacoust.2013.08.006.

[21] Xu, M.B., Selamet, A., Kim, H. (2010). Dual Helmholtz resonator. Applied Acoustics, vol. 71, no. 9, p. 822-829, D0I:10.1016/j.apacoust.2010.04.007.

[22] Davis, D., Stokes, G., Moore, D., Stevens, G. (1954). Theoretical and experimental investigation of mufflers with comments on engine-exhaust muffler design. NACA Annual Report, Langley Aeronautical Laboratory, Langley Field.

[23] Ver, I., Beranek, L. (2006). Noise and Vibration Control Engineering. John Wiley \& Sons, New Jersey.

[24] Peat, K.S. (2010). Acoustic impedance at the interface between a plain and a perforated pipe. Journal of Sound and Vibration, vol. 329, no. 14, p. 2884-2894, D0l:10.1016/j. jsv.2010.01.037.

[25] Selamet, A., Lee, I.J., Huff, N.T. (2003). Acoustic attenuation of hybrid silencers. Journal of Sound and Vibration, vol. 262, no. 3, p. 509-527, DOI:10.1016/S0022-460X(03)00109-3.

[26] Barbieri, R., Barbieri, N. (2006). Finite element acoustic simulation based shape optimization of a muffler. Applied Acoustics, vol. 67, no. 4, p. 346-357, D0l:10.1016/j. apacoust.2005.06.007.

[27] Ji, Z.L., Selamet, A. (2000). Boundary element analysis of three-pass perforated duct mufflers. Noise Control Engineering Journal, vol. 48, no. 5, p. 151-156, D0l:10.3397/1.2827962.

[28] Hu, F.Q. (2001). A stable, perfectly matched layer for linearized euler equations in unsplit physical variables. Journal of Computational Physics, vol. 173, no. 2, p. 455-480, D0I:10.1006/jcph.2001.6887.

[29] Oliva, D., Hongisto, V. (2013). Sound absorption of porous materials - Accuracy of prediction methods. Applied Acoustics, vol. 74, no. 12, p. 1473-1479, DOI:10.1016/j.apacoust.2013.06.004. 